\title{
Genetic landscape of adult Langerhans cell histiocytosis with lung involvement
}

\author{
Fanélie Jouenne ${ }^{1,2}$, Sylvie Chevret ${ }^{3,4}$, Emmanuelle Bugnet ${ }^{5}$, \\ Emmanuelle Clappier ${ }^{6,7}$, Gwenaël Lorillon ${ }^{5}$, Véronique Meignin ${ }^{8}$, \\ Aurélie Sadoux ${ }^{2}$, Shannon Cohen ${ }^{9}$, Alain Haziot ${ }^{9}$, Alexandre How-Kit ${ }^{10}$, \\ Caroline Kannengiesser (1) ${ }^{11}$, Céleste Lebbé ${ }^{1,12}$, Dominique Gossot ${ }^{13}$, \\ Samia Mourah ${ }^{1,2}$ and Abdellatif Tazi ${ }^{1,5}$
}

@ERSpublications

MAPK alterations are present in most lesions from adult pulmonary LCH patients. In patients with refractory progressive disease, the identification of these alterations, including BRAF deletions, is important to guide the choice of targeted treatment. http://bit.ly/2Qoknsn

Cite this article as: Jouenne F, Chevret S, Bugnet E, et al. Genetic landscape of adult Langerhans cell histiocytosis with lung involvement. Eur Respir J 2020; 55: 1901190 [https://doi.org/10.1183/ 13993003.01190-2019].

ABSTRACT The clinical significance of the $B R A F^{\mathrm{V} 600 \mathrm{E}}$ mutation in adult Langerhans cell histiocytosis $(\mathrm{LCH})$, including pulmonary Langerhans cell histiocytosis (PLCH), is not well understood. Similarly, the spectrum of molecular alterations involved in adult LCH has not been fully delineated. To address these issues, we genotyped a large number of adult LCH biopsies and searched for an association of identified molecular alterations with clinical presentation and disease outcome.

Biopsies from 117 adult LCH patients, 83 with PLCH (median age 36.4 years, 56 females, 38 multisystem disease, 79 single system disease, 65 current smokers) were genotyped for the $B R A F^{\mathrm{V} 600 \mathrm{E}}$ mutation. In 69 cases, LCH lesions were also genotyped by whole-exome sequencing (WES) or targeted gene panel next-generation sequencing (NGS). Cox models were used to estimate the association of baseline characteristics with the hazard of $\mathrm{LCH}$ progression.

MAPK pathway alterations were detected in 59 out of 69 cases (86\%) (BRAF ${ }^{\mathrm{V} 600 \mathrm{E}}$ mutation: $36 \%$, $B R A F^{\mathrm{N} 486}{ }^{\mathrm{P} 490}$ deletion: $28 \%, M A P 2 K 1$ mutations: $15 \%$, isolated NRAS ${ }^{\mathrm{Q} 61}$ mutations: 4\%), while KRAS mutations were virtually absent in PLCH lesions. The $B R A F^{\mathrm{V} 600 \mathrm{E}}$ mutation was not associated with $\mathrm{LCH}$ presentation at diagnosis, including smoking status and lung function, in $\mathrm{PLCH}$ patients. BRAF ${ }^{\mathrm{V} 600 \mathrm{E}}$ status did not influence the risk of LCH progression over time.

Thus, MAPK alterations are present in most lesions from adult LCH patients, particularly in PLCH. Unlike reports in paediatric $\mathrm{LCH}, B R A F^{\mathrm{V} 600 \mathrm{E}}$ genotyping did not provide additional information on disease outcome. The search for alterations involved in the MAPK pathway, including BRAF deletions, is useful for guiding targeted treatment in selected patients with refractory progressive LCH. 


\section{Introduction}

Langerhans cell histiocytosis ( $\mathrm{LCH})$ is an inflammatory myeloid neoplasia characterised by accumulation in involved tissues of abnormal cells believed to be of the monocyte/macrophage lineage that harbour pathogenic mutations activating the mitogen-activated protein kinase (MAPK) pathway [1]. LCH can affect patients of all ages, from neonates to the elderly, and it has a wide spectrum of clinical presentations and variable outcomes. In adults, lung involvement (pulmonary Langerhans cell histiocytosis (PLCH)) is commonly observed either as part of multisystem disease or as an isolated LCH localisation and occurs almost exclusively in young adult smokers [2]. The prognosis of PLCH may vary from spontaneous resolution to progressive severe disease leading to respiratory failure and, ultimately, to lung transplantation [2]. With the exception of pulmonary hypertension (PH), PLCH outcome is difficult to predict in an individual patient, with no reliable predictive factors having been identified [2].

Although the presence of the $B R A F^{\mathrm{V} 600 \mathrm{E}}$ mutation in tissue biopsies from adult $\mathrm{LCH}$ patients has been widely reported [3-9], the impact of this mutation on clinical presentation and disease outcome, particularly in PLCH patients, remains elusive [7, 10]. Other alterations of the MAPK pathway (i.e. MAP2K1 mutations) have been identified in LCH lesions, including in the lung $[6-9,11-13]$. In PLCH, we also identified $N R A S^{\mathrm{Q} 61}$ mutations, either isolated or, more frequently, concurrent with $B R A F^{\mathrm{V} 600 \mathrm{E}}$ mutations [7]. Consistent with this finding, KAMATA et al. [14] reported that the expression of $K R A S^{\mathrm{G} 12 \mathrm{D}}$ within myeloid lung cells in mice leads to PLCH-like lesions, although the presence of KRAS mutations has not been accurately assessed in PLCH lesions. Finally, in a substantial proportion of cases, the genomic alterations that could be involved in MAPK activation in adult LCH lesions remain unknown.

To address these issues, we took advantage of the large cohort of adult patients followed in our national reference centre in order to 1) widely genotype a large number of LCH biopsies and 2) search for an association of identified molecular alterations, particularly the $B R A F^{\mathrm{V} 600 \mathrm{E}}$ mutation, with clinical presentation and disease outcome.

\section{Material and methods \\ Patients and Langerhans cell histiocytosis samples}

One hundred and seventeen adult LCH patients (median age 36.4 years, 56 females, 79 with single system disease at diagnosis) were included in this study. Of these patients, 23 were involved in a previous study [7] and 83 (71\%) had PLCH (isolated lung involvement ( $\mathrm{n}=51)$; 65 current smokers and 16 ex-smokers).

This study population was part of 194 patients with histologically confirmed LCH seen at our centre during the same period (figure 1) and were representative of the entire cohort (see supplementary tables S1 and S2 for details).

Formalin-fixed paraffin-embedded (FFPE) LCH biopsies were available for all patients and were evaluated by haematoxylin and eosin (H\&E) staining and anti-CD1a immunostaining (clone O10, Agilent Technologies, les Ulis, France). CD1a-positive areas were macro-dissected for molecular biology analysis [7].

All tissue specimens were genotyped for the presence of $B R A F^{\mathrm{V} 600 \mathrm{E}}$ and $N R A S$ mutations. In 69 cases, 50 with PLCH, the size of the LCH biopsy allowed for comprehensive molecular analysis. Additionally, for 18 of these patients, frozen LCH tissue was also available for whole-exome sequencing (WES). Peripheral blood mononuclear cells (PBMCs) were available for 14 of these samples, which were used as a paired germline control for WES analysis. The remaining four frozen tissue samples without available PBMCs were analysed only for somatic hotspot alterations.

Affiliations: ${ }^{1}$ Université de Paris, INSERM U976, Institut de Recherche Saint-Louis, Paris, France. ${ }^{2}$ Assistance Publique-Hôpitaux de Paris, Hôpital Saint-Louis, Laboratoire de Pharmacogénomique, Paris, France. ${ }^{3}$ Université de Paris, U1153 CRESS, Équipe de Recherche en Biostatistiques et Épidémiologie Clinique (ECSTRRA), Paris, France. ${ }^{4}$ Assistance Publique-Hôpitaux de Paris, Hôpital Saint-Louis, Service de Biostatistique et Information Médicale, Paris, France. ${ }^{5}$ Assistance Publique-Hôpitaux de Paris, Hôpital SaintLouis, Centre National de Référence des Histiocytoses, Service de Pneumologie, Paris, France. ${ }^{6}$ Assistance Publique-Hôpitaux de Paris, Hôpital Saint-Louis, Laboratoire d'Hématologie Biologique, Paris, France. ${ }^{7}$ Université de Paris, INSERM U944, Institut de Recherche Saint-Louis, Paris, France. ${ }^{8}$ Assistance PubliqueHôpitaux de Paris, Hôpital Saint-Louis, Service de Pathologie, INSERM UMR_S1165, Paris, France. ${ }^{9}$ INSERM U1160, Institut de Recherche Saint-Louis, Paris, France. ${ }^{10}$ Laboratoire de Génomique Fonctionnelle, Fondation Jean Dausset - CEPH, Paris, France. ${ }^{11}$ Université de Paris, Assistance Publique-Hôpitaux de Paris, Hôpital Bichat, Laboratoire de Génétique, Paris, France. ${ }^{12}$ Assistance Publique-Hôpitaux de Paris, Hôpital SaintLouis, Département de Dermatologie, Paris, France. ${ }^{13}$ Institut du Thorax Curie-Montsouris, Département Thoracique, Institut Mutualiste Montsouris, Paris, France.

Correspondence: Abdellatif Tazi, Service de Pneumologie, Hôpital Saint-Louis, 1 Avenue Claude Vellefaux, 75475, Paris cedex 10, France. E-mail: abdellatif.tazi@aphp.fr 


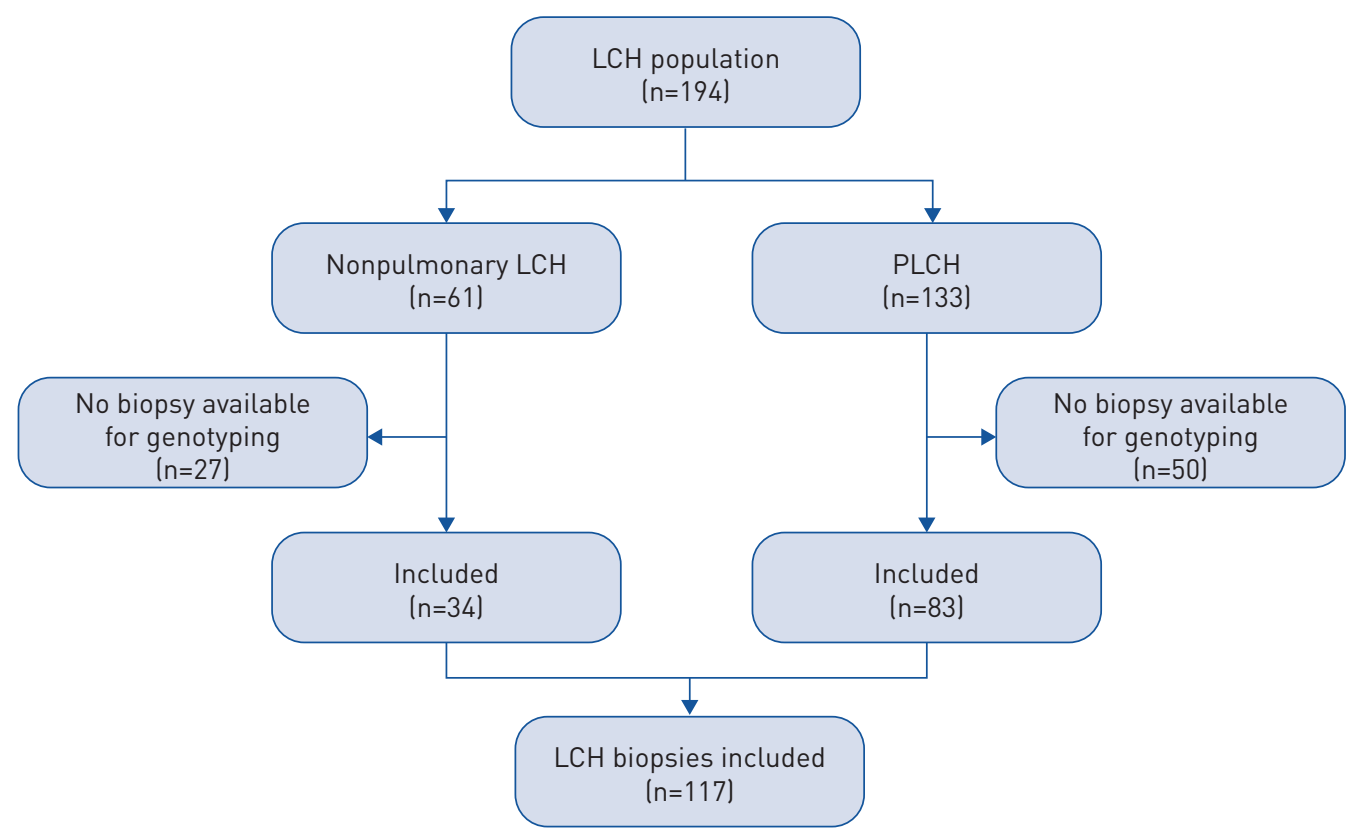

FIGURE 1 Flow chart of the 117 Langerhans cell histiocytosis (LCH) patients included in the study. PLCH: pulmonary Langerhans cell histiocytosis.

In 10 cases, CD11c-positive blood cells (purified from thawed DMSO-frozen PBMCs by flow cytometry as previously described [15]) were available for molecular analysis.

$\mathrm{LCH}$ presentation at the time of biopsy and the molecular genotyping performed on the tissue specimens are shown in supplementary figure S1 and supplementary table S3.

As PLCH occurs almost exclusively in smokers [2], grossly normal lung tissue from 10 smoker patients, obtained at the time of thoracic surgery for localised lung carcinoma, was also genotyped for KRAS.

The study was performed in accordance with the Helsinki Declaration and was approved by the INSERM Institutional Review Board and Ethics Committee in Paris, France (IRB no. 13-130). All patients provided informed consent for the use of their tissue specimens and clinical information for research.

Molecular genotyping techniques

DNA extraction was performed as previously described [7].

Whole-exome sequencing

Whole-exome capture was performed on the genomic platform of the Imagine Institute (Paris, France) using the SureSelect Human All Exon $58 \mathrm{Mb}$ V6 Kit (Agilent Technologies) [16]. Sequencing was conducted on the Illumina HiSeq 2500 platform (Illumina, San Diego, CA, USA). Variants were annotated and analysed using the Polyweb software interface (www.polyweb.fr/) and Alamut software (Interactive Biosoftware, Rouen, France). The mean depth of coverage obtained was 142X (range: 92.60X-257X, mean: 124X for PBMCs and 155X for tissue biopsies), with $>98 \%$ and $>96 \%$ of the targeted exonic bases covered by at least 15 and 30 independent sequencing reads, respectively (see supplementary material for details).

Gene panel next-generation sequencing

A custom-designed next-generation sequencing (NGS) panel of 74 genes involved in MAPK, phosphoinositide 3-kinase, cell cycle and tyrosine kinase receptor signalling pathways $[12,13,17]$ was used for the comprehensive genotyping of LCH tissue biopsies (supplementary table S4). In addition, a custom-designed NGS panel of 78 genes involved in myeloid haematological disorders [18] was performed on frozen LCH specimens (supplementary table S5).

Pyrosequencing

$B R A F^{V 600 E}$ and $N R A S^{G 12 / G 13 / Q 61}$ genotyping was performed as previously described [7]. BRAF exon 12 deletions described in paediatric LCH [19] were searched using a specific custom-designed pyrosequencing assay (see supplementary material and supplementary figure S2 for details). 
Enhanced ice-COLD-PCR

The sensitive detection of mutations in BRAF codon 600, NRAS codons 12, 13 and 61, and KRAS codons 12 and 13 was performed by enhanced ice-COLD-PCR (E-ice-COLD-PCR; improved and complete enrichment coamplification at lower denaturation temperature PCR) [7].

\section{Data collection}

Data on patient demographics, smoking habits, clinical symptoms and signs, LCH localisation and lung function tests at the time of diagnosis and during follow-up, as well as systemic treatments for $\mathrm{LCH}$ received by the patients during the study, were retrieved from the database. Patients were categorised as having single system or multisystem disease according to the Histiocyte Society criteria [20].

During follow-up, based on the global outcome of their disease, LCH patients were classified as having nonactive disease if all signs and symptoms had resolved. Otherwise, they were classified as having active disease, which was further subdivided into better, stable or worse [20]. All patients who received systemic treatment for their $\mathrm{LCH}$ were categorised as having progressive disease.

The outcome of LCH lung involvement was based on variations over time of lung function tests and/or the occurrence of a new pneumothorax during follow-up [21]. Lung volumes were evaluated by plethysmography, forced expiratory volume in $1 \mathrm{~s}\left(\mathrm{FEV}_{1}\right)$ and forced vital capacity $(\mathrm{FVC})$ by the flowvolume curve. Diffusing capacity of the lung for carbon monoxide $\left(D_{\mathrm{LCO}}\right)$ was measured using the single-breath method and the predictive values were determined as previously described [21]. A worsening of lung function was defined as a decrease of $15 \%$ or more in $\mathrm{FEV}_{1}, \mathrm{FVC}$ and/or $D_{\mathrm{LCO}}$ values compared with baseline values [21]. Patients who developed chronic respiratory failure, who were receiving long-term supplemental oxygen and/or who had developed $\mathrm{PH}$, were classified as having progressive lung disease. It is noteworthy that multisystem LCH patients with lung involvement could have progressed either because of the global outcome of their disease and/or because of lung disease progression. Finally, at the time of last follow-up, patient status (alive or deceased) was recorded.

\section{Statistical analysis}

Summary statistics that included means with standard deviation, medians with interquartile range (IQR), or percentages were calculated.

The distribution of right-censored end points (time to progression or death) was estimated by the KaplanMeier method. Univariable Cox models were used to estimate the strength of the association of baseline characteristics, including mutations, as measured by the hazard ratio on the hazard of progression. Variables selected with the outcome at the 5\% level were introduced into a multivariable Cox model. Model selection was performed using a stepwise procedure based on the Akaike information criterion.

Statistical analyses were performed using SAS (SAS Inc., Cary, NC, USA) and R (www.R-project.org/) software. All tests were two-sided, with p-values of 0.05 denoting statistical significance.

\section{Results}

Landscape of molecular abnormalities detected in LCH lesions

WES analysis, performed on frozen tumour lesions from $14 \mathrm{LCH}$ patients (11 PLCH) with a matched PBMC specimen, revealed an average number of 14 somatic mutations targeting an average of 13 genes (table 1). Four additional frozen lesions were analysed for somatic hotspot alterations.

A $B R A F^{\mathrm{V} 600 \mathrm{E}}$ mutation or $B R A F^{\mathrm{N} 486-{ }^{\mathrm{P} 490}}$ deletion was detected in 14 lesions and MAP2K1 alterations were detected in two lesions. Additionally, NRAS ${ }^{\mathrm{G} 12 \mathrm{D}}$ and $N R A S^{\mathrm{Q} 61 \mathrm{~K}}$ mutations were identified in one and three lesions, respectively, concurrently with a $B R A F^{\mathrm{V} 600 \mathrm{E}}$ mutation. Hence, a genomic alteration activating the MAPK pathway was identified in 16 out of $18 \mathrm{LCH}$ cases (89\%).

Among the additional mutations identified, two missense mutations predicted to be deleterious (based on the algorithms used) were detected in two distinct lesions (NT5C1B-RDH14 ${ }^{\mathrm{R} 191 \mathrm{H}}$ and $C P^{\mathrm{G} 895 \mathrm{~A}}$ ) and three frameshift alterations were detected in three other lesions (a small insertion in CIC and UNC5B, and a small deletion in DTHD1) (table 1).

As there is a known association of myeloid malignancies with a histiocytic disorder related to LCH known as Erdheim-Chester disease (ECD) [22], we investigated 17 of these 18 frozen LCH biopsies using a custom-designed NGS panel for myeloid disorders. In one LCH lesion (skin biopsy), two pathogenic mutations were identified in TET2 (Q114X, variant allele frequency (VAF) 12\% and G1370R, VAF 5\%), as well as an in-frame internal tandem duplication (ITD) in FLT3 (FLT3-ITD), which were present concurrently with $B R A F^{\mathrm{V} 600 \mathrm{E}}$ and $N R A S^{\mathrm{G} 12 \mathrm{D}}$ mutations. 
TABLE 1 Selection of variants detected by whole-exome sequencing (WES) using the Polyweb interface (www.polyweb.fr/) for the 14 lesions analysed with a matched peripheral blood mononuclear cells (PBMC) control sample

\begin{tabular}{|c|c|c|c|c|c|c|c|c|c|c|}
\hline Gene & Variation $\rrbracket$ & Type & $\begin{array}{c}\text { Patient } \\
\text { number (VAF) }\end{array}$ & Consequence & Description & Exon & $\begin{array}{l}\text { Amino acid } \\
\text { variant }\end{array}$ & $\begin{array}{l}\text { Genomic } \\
\text { variant }\end{array}$ & PolyPhen2 & SIFT \\
\hline$B R A F$ & 7_140453136_A_T (rs113488022) & SNV & $\begin{array}{c}10(10 \%) \\
23(4 \%) \\
27(1 \%) \\
56(4 \%) \\
59(2 \%) \\
103(11 \%)\end{array}$ & Missense & $\begin{array}{l}\text { V-raf murine sarcoma } \\
\text { viral oncogene homolog B }\end{array}$ & 15 & V600E & c. $1799 \mathrm{~T}>\mathrm{A}$ & $\begin{array}{l}\text { Probably } \\
\text { damaging }\end{array}$ & Deleterious \\
\hline BRAF & $\begin{array}{l}\text { 7_140477837_- } \\
\text { AATGTGACAGCACCTA_A }\end{array}$ & Deletion & $\begin{array}{c}8(2.5 \%) \\
16(12 \%) \\
30(4 \%) \\
31(2 \%)\end{array}$ & $\begin{array}{l}\text { In-frame } \\
\text { deletion }\end{array}$ & $\begin{array}{l}\text { V-raf murine sarcoma } \\
\text { viral oncogene homolog B }\end{array}$ & 12 & LNVTAPT486LT & $\begin{array}{l}\text { c. } 1457- \\
1471 \mathrm{del}^{\S}\end{array}$ & - & - \\
\hline$C I C$ & 19_42799295_A_AG & Insertion & $67(34 \%)$ & Frameshift & $\begin{array}{l}\text { Capicua transcriptional } \\
\text { repressor }\end{array}$ & 20 & Q1593QA & $\begin{array}{l}\text { c.4778 } \\
4779 \text { ins }^{f}\end{array}$ & - & - \\
\hline$C P$ & 3_148896396_C_G (rs139633388) & SNV & $57(10 \%)$ & Missense & Ceruloplasmin (ferroxidase) & 16 & G895A & c. $2684 G>C$ & $\begin{array}{l}\text { Probably } \\
\text { damaging }\end{array}$ & Deleterious \\
\hline DTHD1 & 4_36285990_TAAAC_T & Deletion & $57(10 \%)$ & Frameshift & Death domain containing 1 & 1 & KQ97X & c.289_292del ${ }^{\S}$ & - & - \\
\hline HMCN1 & 1_186086719_C_Ā (rs376333827) & SNV & $57(21 \%)$ & Missense & Hemicentin 1 & 77 & L3938I & c. $11812 \mathrm{C}>\mathrm{A}$ & $\begin{array}{l}\text { Possibly } \\
\text { damaging }\end{array}$ & Benign \\
\hline MAP2K1 & 15_66729093_TCTGGA_T & Deletion & $2(14 \%)$ & Frameshift & MAPK kinase 1 & 3 & L101Dfs*18+ & c.301_305del ${ }^{\S}$ & - & - \\
\hline MAP2K1 & 15_66729093_TGGAGAT_T & Deletion & $57(7 \%)$ & $\begin{array}{l}\text { In-frame } \\
\text { deletion }\end{array}$ & MAPK kinase 1 & 3 & LEIK 102LK & c.303_308del ${ }^{\S}$ & - & - \\
\hline NRAS & 1_115256530_G_T (rs121913254) & SNV & $\begin{array}{l}10(14 \%) \\
27(4 \%) \\
59(8 \%)\end{array}$ & Missense & $\begin{array}{l}\text { V-ras neuroblastoma RAS } \\
\text { viral oncogene homolog }\end{array}$ & 3 & Q61K & c. $181 \mathrm{C}>\mathrm{A}$ & $\begin{array}{c}\text { Possibly } \\
\text { damaging }\end{array}$ & Deleterious \\
\hline NT5C1B-RDH14 & 2_18765937_C_T & SNV & $103(15 \%)$ & Missense & $\begin{array}{l}\text { NT5C1B-RDH14 } \\
\text { readthrough }\end{array}$ & 4 & $\mathrm{R} 191 \mathrm{H}$ & c. $572 \mathrm{G}>\mathrm{A}$ & $\begin{array}{l}\text { Probably } \\
\text { damaging }\end{array}$ & Deleterious \\
\hline PCLO & 7_82584553_C_A (rs202091944) & SNV & $57(17 \%)$ & Missense & $\begin{array}{l}\text { Piccolo presynaptic } \\
\text { cytomatrix protein }\end{array}$ & 5 & G1906C & c. $5716 G>T$ & $\begin{array}{l}\text { Probably } \\
\text { damaging }\end{array}$ & Benign \\
\hline PPFIA2 & 12_81657159_T_C (rs368764392) & SNV & $57(15 \%)$ & Missense & $\begin{array}{c}\text { PTPRF } \\
\text { Interacting protein (liprin), alpha } 2\end{array}$ & 31 & K1189R & c. $3566 \mathrm{~A}>\mathrm{G}$ & Benign & Deleterious \\
\hline UNC5B & $\begin{array}{c}\text { 10_73056470_G_GATATTCCAGCTGC } \\
\text { ATACCACTCTGGCAGAGGTGAGGGAAG } \\
\text { TCGGGGCCAC (rs879908823) }\end{array}$ & Insertion & $71(50 \%)$ & Frameshift & $\begin{array}{l}\text { Unc-5 homolog B } \\
\text { (Caenorhabditis elegans) }\end{array}$ & 15 & I821IF & $\begin{array}{l}\text { c.2460 } \\
2461 \text { ins }^{f}\end{array}$ & - & - \\
\hline
\end{tabular}

VAF: variant allele frequency; SIFT: Sorting Intolerant from Tolerant (https://sift.bii.a-star.edu.sg); SNV: single nucleotide variant; MAPK: mitogen-activated protein kinase; PTPRF: protein tyrosine phosphatase, receptor type, f polypeptide. \# : eleven patients had pulmonary Langerhans cell histiocytosis (PLCH) at diagnosis; ${ }^{\text {? }}$ : variation format: chromosome_genomic position_allele reference_allele mutated (rs number); ${ }^{+}: \mathrm{fs}^{*} 18$ is a variant that causes a frameshift (the new reading frame ends on a downstream 18-position STOP codon); : del=deletion; ${ }^{f}$ : ins=insertion. 
Since the identified mutations mainly involved the MAPK pathway, we extended the genomic analysis to a larger series of LCH lesions using a custom-designed NGS panel of 74 genes including MAPK pathway genes. Among the $69 \mathrm{LCH}(50 \mathrm{PLCH})$ lesions analysed, including the 18 lesions sequenced by WES, a BRAF alteration was identified in 46 cases $(67 \%)$ and consisted of $25 B R A F^{\mathrm{V} 600 \mathrm{E}}$ mutations (36\%), 20 BRAF ${ }^{\mathrm{N} 486 \_\mathrm{P} 490}$ deletions (29\%, present concurrently with a $B R A F^{\mathrm{V} 600 \mathrm{E}}$ mutation in one case) and one $B R A F^{\mathrm{G} 469 \mathrm{~A}}$ mutation (lung biopsy). The $B R A F^{\mathrm{G} 469 \mathrm{~A}}$ mutation was previously identified in BRAF-mutated lung adenocarcinomas [23]. This mutation belongs to class 2 of the BRAF mutants and is insensitive to the BRAF inhibitor vemurafenib [24].

$M A P 2 K 1$ alterations were detected in 10 lesions (14.5\%) and consisted of six MAP2K1 mutations and four $M A P 2 K 1$ deletions. All mutations were localised to exons 2 and 3, encoding the autoregulatory domain and the catalytic core of MAP2K1 (also called MEK1). Five of these mutations are activating: Q56P [25], K57N [26], the E102_I103 deletion [12], G128D and C121S [13]. An R108W mutation not functionally evaluated previously was identified in one case. This mutation, located in the protein kinase catalytic domain, was predicted to be deleterious by $3 / 3$ algorithms and was shown by peptide arrays to have a critical role in the surface of MEK1 for tubulin interaction [27]. Another case harboured an undescribed L101Dfs ${ }^{\star} 18$ frameshift deletion, which generates a stop codon 18 positions downstream.

Isolated $N R A S^{\mathrm{Q} 61}$ mutations were observed in three cases (two lung tissue and one bone tissue). In addition, 11 other lesions (lung $(\mathrm{n}=8)$ and skin $(\mathrm{n}=3))$ harboured NRAS mutations $\left(N R A S^{\mathrm{G} 12 \mathrm{D}}(\mathrm{n}=2)\right.$ and NRAS ${ }^{\mathrm{Q} 61}$ $(\mathrm{n}=9))$ in association with other alterations $\left(B R A F^{\mathrm{V} 600 \mathrm{E}}\right.$ in nine cases). Finally, one isolated $K R A S^{\mathrm{G} 12 S}$ mutation was observed in a skin biopsy and only one lung biopsy sample harboured a $K R A S^{\mathrm{G} 12 \mathrm{D}}$ mutation, which was identified concurrently with a $B R A F^{\mathrm{V} 600 \mathrm{E}}$ mutation and an NRAS ${ }^{\mathrm{Q} 61 \mathrm{R}}$ mutation. No KRAS ${ }^{\mathrm{G} 12 \mathrm{D}}$ mutations were identified by NGS in the control lung tissue obtained from 10 smokers. All these findings were confirmed by at least one additional genotyping technique (pyrosequencing and/or E-Ice-COLD-PCR).

Overall, a pathogenic alteration of the MAPK pathway was observed in 59 of the 69 tested lesions (86\%; see table 2 and figures 2 and 3). More precisely, 44 of the $50 \mathrm{PLCH}$ patients' lesions (88\%) contained a MAPK alteration. Several other mutations that could potentially be involved in LCH pathogenesis were identified concurrently with MAPK alterations (see table 2 and figure 2, and detailed in supplementary table S6). The prevalence of the identified molecular alterations did not significantly differ according to the site of LCH biopsy $(\mathrm{p}=0.60)$.

No MAPK alterations could be identified in purified CD11c ${ }^{+}$blood cells available from $10 \mathrm{LCH}$ patients (six multisystem), although eight out of 10 paired lesions harboured genomic alterations.

\section{Correlation between MAPK alterations and clinical features}

For the $69 \mathrm{LCH}$ patients whose lesions were widely genotyped, no difference in clinical features was identified according to the different MAPK alterations, both at diagnosis and during follow-up. The cumulative incidence of $\mathrm{LCH}$ progression during the study period was not different according to the different mutations identified (figure 4; $\mathrm{p}=0.6$, Gray's test).

As the $B R A F^{\mathrm{V} 600 \mathrm{E}}$ mutation is a driving mutation in $\mathrm{LCH}$ and was shown to be correlated with $\mathrm{LCH}$ severity in paediatric LCH $[15,28]$, we specifically evaluated the clinical impact of this mutation. Notably, in other MAPK related diseases and particularly in melanoma, this mutation was shown to be an independent prognostic factor, whereas other MAPK activating mutations did not have the same prognostic impact $[29,30]$. For this purpose, 48 additional patients whose LCH tissues were genotyped for $B R A F^{\mathrm{V} 600 \mathrm{E}}$ were included in this analysis (mutated in $37.5 \%$ of cases). The characteristics of $\mathrm{LCH}$ at diagnosis were comparable to those of the 69 patients whose lesions were widely genotyped, with the exception that the latter were somewhat younger $(\mathrm{p}=0.051)$ and had bone involvement less frequently $(\mathrm{p}=0.04)$. Considering the entire study population $(\mathrm{n}=117)$, no association was found between $B R A F^{\mathrm{V} 600 \mathrm{E}}$ status and LCH presentation at diagnosis (table 3).

Among the $83 \mathrm{PLCH}$ patients, no difference in smoking status ( $\mathrm{p}=0.42)$ or the proportion of pneumothorax $(\mathrm{p}=0.29)$ was identified according to the presence or absence of the $B R A F^{\mathrm{V} 600 \mathrm{E}}$ mutation in tissue lesions. Lung function at diagnosis was available for 73 patients (88\%) in comparable proportions for patients with and without the $B R A F^{\mathrm{V} 600 \mathrm{E}}$ mutation. The proportion of restrictive pattern, airflow obstruction, or impairment of $D_{\mathrm{LCO}}(<80 \%$ of predicted values) was similar between the two groups of patients $(\mathrm{p}=0.088, \mathrm{p}=0.44$ and $\mathrm{p}=0.11$, respectively).

Patients were followed for a median time of 59.5 months (IQR 32-117.5) and, based on the global outcome of LCH, 70 patients overall (60\%) experienced a progression of LCH during the study period. This consisted of progression in $18 \mathrm{LCH}$ patients without pulmonary involvement and in 52 patients with LCH lung localisation at diagnosis. It is noteworthy that only 38 of the latter 52 were related to lung progression in 
TABLE 2 Results of genotyping of the 69 patients whose Langerhans cell histiocytosis (LCH) lesions were widely genotyped by next-generation sequencing (NGS) and pyrosequencing for BRAF deletions

\begin{tabular}{|c|c|}
\hline Patient & Predominant variant \\
\hline 1 & $B R A F^{\mathrm{V} 600 \mathrm{E}}$ \\
\hline 2 & MAP2K1 $1^{\text {L101Dfs*18 }}$ \\
\hline $3^{\#}$ & $B R A F^{\mathrm{N} 486}{ }^{\mathrm{P} 490}$ deletion \\
\hline $4^{\#}$ & MAP $2 K 1^{\mathrm{C} 121 \mathrm{~S}}$ \\
\hline $5^{\#}$ & $\mathrm{MAP} 2 \mathrm{~K} 1^{\mathrm{R} 108 \mathrm{~W}}$ \\
\hline $6^{\#}$ & $B R A F^{\mathrm{N} 486 \_\mathrm{P} 490}$ deletion \\
\hline $\mathbf{7}^{\#}$ & $M A P 2 K 1^{\mathrm{G} 128 \mathrm{D}}$ \\
\hline $8^{\#}$ & $B R A F^{\mathrm{N} 486}{ }^{\mathrm{P} 490}$ deletion \\
\hline $9^{\#}$ & WT \\
\hline $10^{\#}$ & $B R A F^{\mathrm{V} 600 \mathrm{E}}$ \\
\hline $11^{\#}$ & $M A P 2 K 1^{G 128 D}$ \\
\hline 12 & $B R A F^{\mathrm{V} 600 \mathrm{E}}$ \\
\hline $13^{\#}$ & $B R A F^{\mathrm{N} 486-\mathrm{P} 490}$ deletion \\
\hline $14^{\#}$ & WT \\
\hline 15 & $B R A F^{\mathrm{N} 486-\mathrm{P} 490}$ deletion \\
\hline $16^{\#}$ & $B R A F^{\mathrm{N} 486}{ }^{\mathrm{P} 490}$ deletion \\
\hline $17^{\#}$ & $B R A F^{\mathrm{V} 600 \mathrm{E}}$ \\
\hline $18^{\#}$ & $B R A F^{\mathrm{V} 600 \mathrm{E}}$ \\
\hline
\end{tabular}

$19^{\#}$

20

21 \#

$22^{\#}$

$23^{\#}$

$24^{\#}$

$25^{\#}$

$26^{\#}$

$27^{\#}$

28

29

$30^{\#}$

$31^{\#}$

$32^{\#}$

$33^{\#}$

$34^{\#}$

$35^{\text {\# }}$

36 \#

$37^{\text {\# }}$

$38^{\#}$

39

$40^{\#}$

$41^{\#}$

$42^{\#}$

$43^{\#}$

$44^{\#}$

$45^{\#}$

$46^{\#}$

47
WT

$B^{2} F^{\mathrm{V} 600 \mathrm{E}}$

BRAF ${ }^{\mathrm{N} 486 \_\mathrm{P} 490}$ deletion

NRAS ${ }^{\mathrm{Q} 1 \mathrm{~K}}$

$B R A F^{\mathrm{V} 600 \mathrm{E}}$

WT

$B R A F^{\mathrm{V} 600 \mathrm{E}}$

$B R A F^{\mathrm{V} 600 \mathrm{E}}$

BRAF ${ }^{\mathrm{V} 600 \mathrm{E}}$

$B R A F^{\mathrm{N} 486-\mathrm{P} 490}$ deletion WT

$B R A F^{\mathrm{N} 486}{ }^{\mathrm{P} 490}$ deletion BRAF N486 P490 delion BRAF ${ }^{\mathrm{N} 486}{ }^{\mathrm{P} 490}$ deletion

$$
B R A F^{\mathrm{V} 600 \mathrm{E}}
$$

BRAF ${ }^{\text {nonV600E }}$ (G469A)

MAP2K1 $1^{\text {102_I103 deletion }}$ BRAF ${ }^{\mathrm{V} 600 \mathrm{E}}$ $B R A F^{\mathrm{V} 600 \mathrm{E}}$

MAP2K1 ${ }^{\text {E102_I103 }}$ deletion $B R A F^{\mathrm{V} 600 \mathrm{E}}$ BRAF $\mathrm{V} 600 \mathrm{E}$ $B R A F^{\mathrm{N} 486}{ }^{\mathrm{P} 490}$ deletion

$B R A F^{\mathrm{V} 600 \mathrm{E}}$

$B R A F^{\mathrm{V} 600 \mathrm{E}}$

$B R A F^{\mathrm{V} 600 \mathrm{E}}$

$B R A F^{\mathrm{V} 600 \mathrm{E}}$

$B R A F^{\mathrm{N} 486-\mathrm{P} 490}$ deletion

BRAF ${ }^{\mathrm{V} 600 \mathrm{E}}$
Additional variants

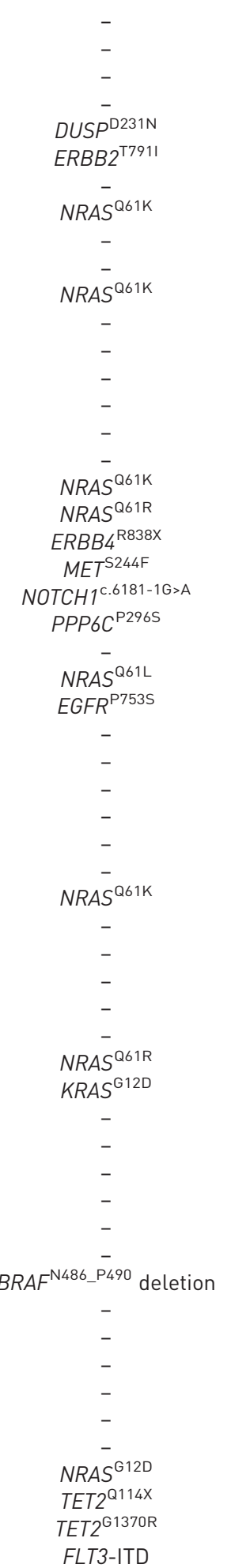


TABLE 2 Continued

\begin{tabular}{|c|c|c|}
\hline Patient & Predominant variant & Additional variants \\
\hline $49^{\#}$ & $B R A F^{\mathrm{N} 486 \_\mathrm{P} 490}$ deletion & $N R A S^{Q 61 R}$ \\
\hline 50 & $B R A F^{\mathrm{V} 600 \mathrm{E}}$ & $N R A S^{G 12 D}$ \\
\hline $51^{\#}$ & $B R A F^{\mathrm{V} 600 \mathrm{E}}$ & - \\
\hline $52^{\#}$ & $B R A F^{\mathrm{N} 486 \_\mathrm{P} 490}$ deletion & - \\
\hline 53 & $B R A F^{\mathrm{N} 486 \_\mathrm{P} 490}$ deletion & - \\
\hline 54 & WT & - \\
\hline 55 & $N R A S^{Q 61 R}$ & - \\
\hline $56^{\#}$ & $B R A F^{\mathrm{V} 600 \mathrm{E}}$ & - \\
\hline 57 & MAP2K1E102_1103 deletion & $I D H 1^{G 105 D}$ \\
\hline $58^{\#}$ & $N R A S^{Q 61 \mathrm{~K}}$ & - \\
\hline $59^{\#}$ & $B R A F^{\mathrm{V} 600 \mathrm{E}}$ & $N R A S^{Q 61 K}$ \\
\hline $60^{\#}$ & $M A P 2 K 1^{Q 56 P}$ & - \\
\hline 61 & $B R A F^{\mathrm{V} 600 \mathrm{E}}$ & - \\
\hline $62^{\#}$ & $B R A F^{\mathrm{N} 486 \_\mathrm{P} 490}$ deletion & - \\
\hline 63 & $K R A S^{G 12 S}$ & - \\
\hline 64 & $B R A F^{\mathrm{N} 486 \_\mathrm{P} 490}$ deletion & - \\
\hline 65 & WT & - \\
\hline $66^{\#}$ & $B R A F^{\mathrm{N} 486 \_\mathrm{P} 490}$ deletion & - \\
\hline $67^{\#}$ & WT & - \\
\hline $68^{\#}$ & MAP $2 K 1^{\mathrm{K} 57 \mathrm{~N}}$ & - \\
\hline 69 & WT & - \\
\hline
\end{tabular}

WT: wild type; ITD: internal tandem duplication. " : patients with pulmonary Langerhans cell histiocytosis (PLCH) at diagnosis $(n=50)$.

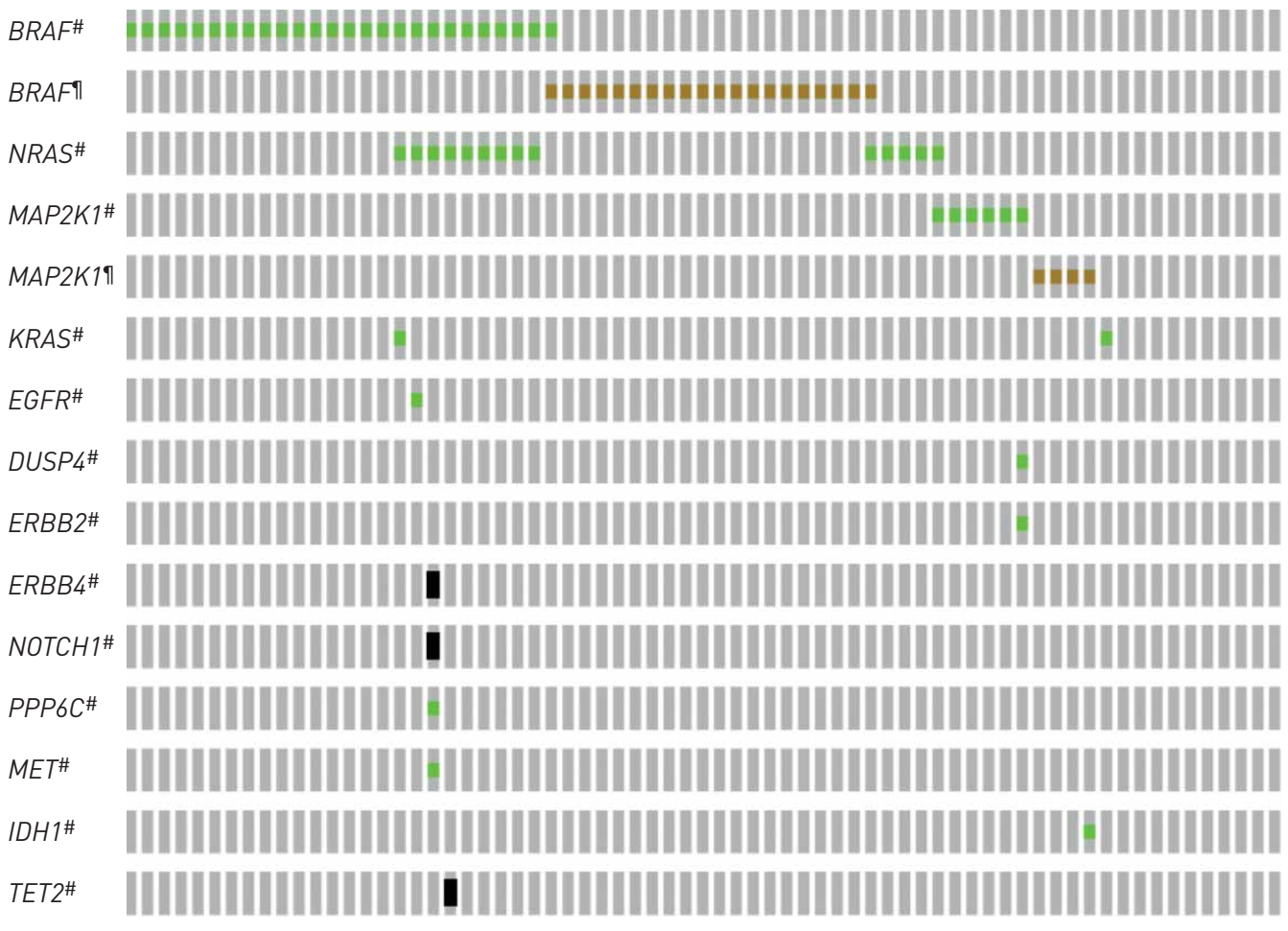

FIGURE 2 Mutational landscape in 69 Langerhans cell histiocytosis (LCH) patients whose lesions were widely genotyped by next-generation sequencing (NGS) and pyrosequencing for BRAF deletions. The basic plot was created using cBioPortal (www.cbioportal.org/) and the altered genes are listed on the left-hand side of the diagram. All BRAF mutations are BRAF ${ }^{\mathrm{V} 600 \mathrm{E}}$ mutations except for one, which is a $B R A F^{\mathrm{G} 469 \mathrm{~A}}$ mutation. The $B R A F, N R A S, M A P 2 K 1, K R A S, E G F R, D U S P 4, E R B B 2, E R B B 4$ and MET genes belong to, or are linked to, the mitogen-activated protein kinase (MAPK) pathway, and IDH1 and TET2 belong to the family of epigenetic modifiers. \# : mutation; П: small deletion. 
FIGURE 3 Distribution of mitogen-activated protein kinase (MAPK) alterations among the 69 Langerhans cell histiocytosis (LCH) patients whose lesions were evaluated by next-generation sequencing (NGS) and pyrosequencing for BRAF deletions (displayed as percentages of identified MAPK alterations). MAP2K1 comprises both mutations and deletions. Concurrent genomic alterations were not recorded. WT: wild type.

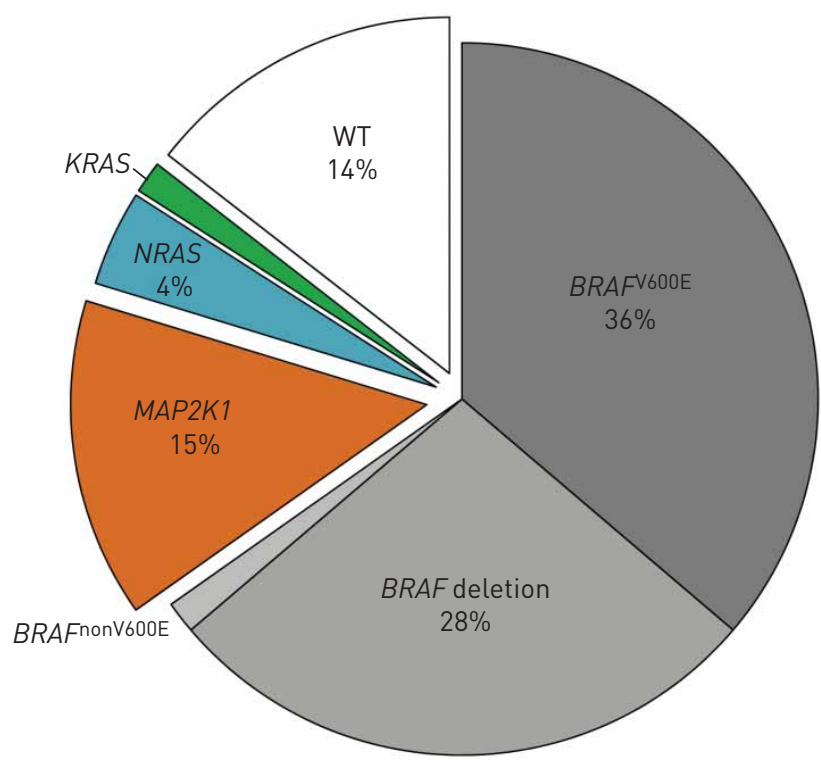

PLCH patients. Thirty-seven patients needed systemic LCH treatment, consisting mainly of corticosteroids associated with vinblastine and/or cladribine. A comparable proportion of patients with and without $B R A F^{\mathrm{V} 600 \mathrm{E}}$ mutated lesions received systemic $\mathrm{LCH}$ treatment ( $\mathrm{p}=0.21$, Fisher's exact test). Seven patients (6\%) died (five linked to $\mathrm{LCH}$ ) and two received transplants due to lung involvement. The probability of disease progression over time was similar regardless of the $B R A F^{\mathrm{V} 600 \mathrm{E}}$ status of the lesions (figure $5 \mathrm{a}$ ).

Among the PLCH population, 38 patients (46\%) experienced lung progression (including 10 patients with respiratory failure, long-term oxygen use, or $\mathrm{PH}) . B R A F^{\mathrm{V} 600 \mathrm{E}}$ status was not associated with lung involvement outcome (figure 5b; $\mathrm{p}=0.55$, Gray's test).

In the univariable analysis, an older age at diagnosis was associated with an increased risk of disease progression in patients (hazard ratio 1.37 per decade, $95 \%$ CI $1.04-1.80 ; p=0.027$ ), including the group of PLCH patients (hazard ratio 1.37, 95\% CI 1.02-1.80; $\mathrm{p}=0.027$ ). Additionally, the presence of airflow obstruction was associated with lung progression (supplementary table S7). In the multivariable analysis, only the presence of airflow obstruction remained associated with an increased risk of lung progression (hazard ratio $2.00,95 \%$ CI 1.05-3.84; $\mathrm{p}=0.036$ ) (table 4).

FIGURE 4 Cumulative incidence of disease progression among the 69 Langerhans cell histiocytosis (LCH) patients whose lesions were widely genotyped, according to the different mitogen-activated protein kinase (MAPK) alterations identified (BRAF ${ }^{\mathrm{V} 600 \mathrm{E}}(\mathrm{n}=25) ;$ other BRAF alterations $(\mathrm{n}=21 ;$ BRAF deletions $(\mathrm{n}=19)$, other $(\mathrm{n}=2))$; non-BRAF alterations $(n=14 ; \quad M A P 2 K 1 \quad(n=10)$, NRAS/KRAS (n=4)); wild type (WT; $\mathrm{n}=9)$.

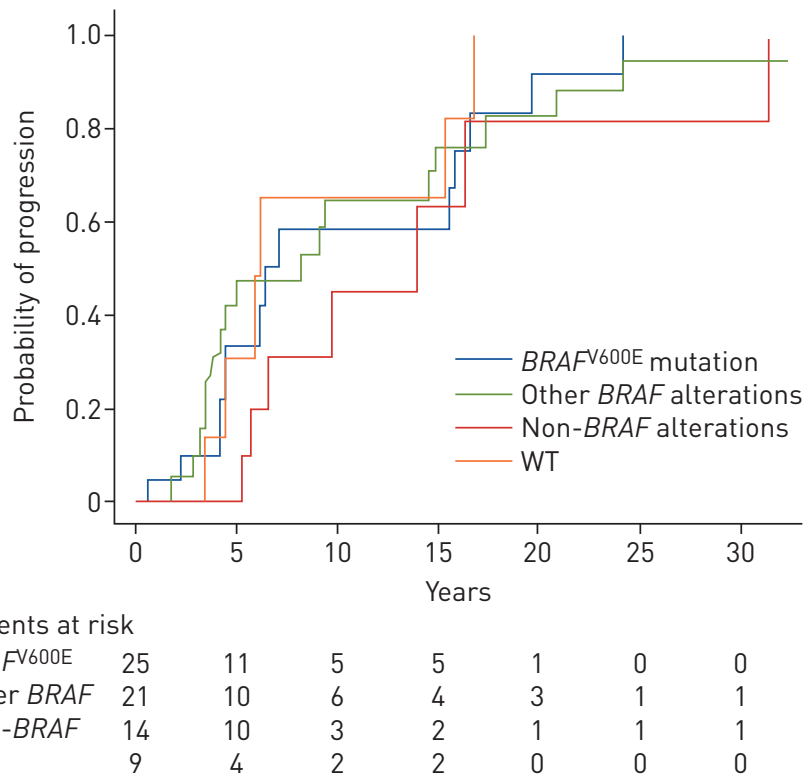


TABLE 3 Comparison of clinical features at diagnosis of the 117 Langerhans cell histiocytosis (LCH) patients according to the BRAF ${ }^{\mathrm{V} 600 \mathrm{E}}$ status of their lesions

\begin{tabular}{lccc} 
Characteristic & $B R A F^{\mathrm{V} 600 E}(\mathbf{n = 4 3 )}$ & Without $B R A F^{\mathrm{V} 600 E}(\mathbf{n = 7 4 )}$ & p-value \\
\hline Female & $20(46.5)$ & $36(48.6)$ & 0.85 \\
Age years & $38.0(26.6-50.0)$ & $35.2(25.0-45.8)$ & 0.24 \\
Multisystem & $12(27.9)$ & $26(35.1)$ & 0.54 \\
Organs involved ${ }^{\#}$ & & & 0.78 \\
$\quad 1$ & $31(72)$ & $48(64.9)$ & - \\
2 & $7(16.3)$ & $16(21.6)$ & - \\
3 & $2(4.7)$ & $6(8.1)$ & - \\
4 & $3(7)$ & $4(5.4)$ & - \\
Lung & $31(72.1)$ & $52(70.3)$ & 1.00 \\
Bone & $10(23.3)$ & $23(31.1)$ & 0.40 \\
Pituitary & $6(13.9)$ & $10(13.5)$ & 1.00 \\
Skin & $7(16.3)$ & $12(16.2)$ & 1.00 \\
Lymph node & $3(7)$ & $6(8.1)$ & 1.00 \\
\hline
\end{tabular}

Data is presented as $\mathrm{n}(\%)$ or median (interquartile range $(I Q R))$ unless otherwise stated. *: risk organ involvement (liver or haematological involvement) and central nervous system localisation were not assessed, as they concerned only three patients each in the entire study population; " ${ }^{\text {I }}$ diabetes insipidus (associated (or not) with anterior hypophysis deficiency).

\section{Discussion}

In this study, we found the following salient results: 1) MAPK alterations were present in nearly $90 \%$ of the $\mathrm{LCH}$ lesions; 2) besides $B R A F^{\mathrm{V} 600 \mathrm{E}}$ mutations, $B R A F^{\mathrm{N} 486 \_\mathrm{P} 490}$ deletions were identified in a substantial proportion of cases; 3) KRAS mutations were virtually absent from PLCH lesions; and 4) BRAF $F^{\mathrm{V} 600 \mathrm{E}}$ mutation was not associated with either the initial presentation or the outcome of PLCH.

MAPK alterations were present in $86 \%$ of the LCH biopsies evaluated by NGS and only a small minority of cases were found to be wild type (WT). Moreover, because we did not perform RNA sequencing on tissue specimens, we cannot exclude the possibility that additional MAPK alterations, such as BRAF kinase fusion, were missed $[19,31]$. Thus, in the vast majority of adult LCH cases, particularly PLCH cases, the disease appears to be driven by genomic alterations involving the MAPK pathway.

The $B R A F^{\mathrm{V} 600 \mathrm{E}}$ mutation was identified in $36 \%$ of cases and in similar percentages among the subgroups of patients whose lesions were evaluated by NGS or by gene-specific genotyping. This frequency of $B R A F^{\mathrm{V} 600 \mathrm{E}}$ mutations was significantly lower than the $64 \%$ observed by CHAKRABORTY et al. [19] in

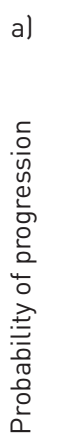

a)

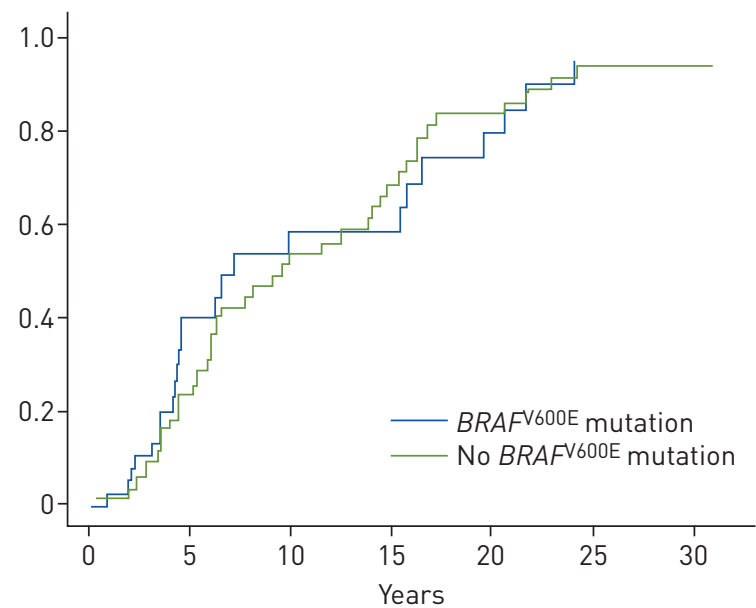

Patients at risk

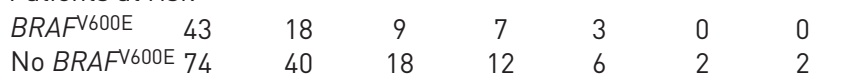

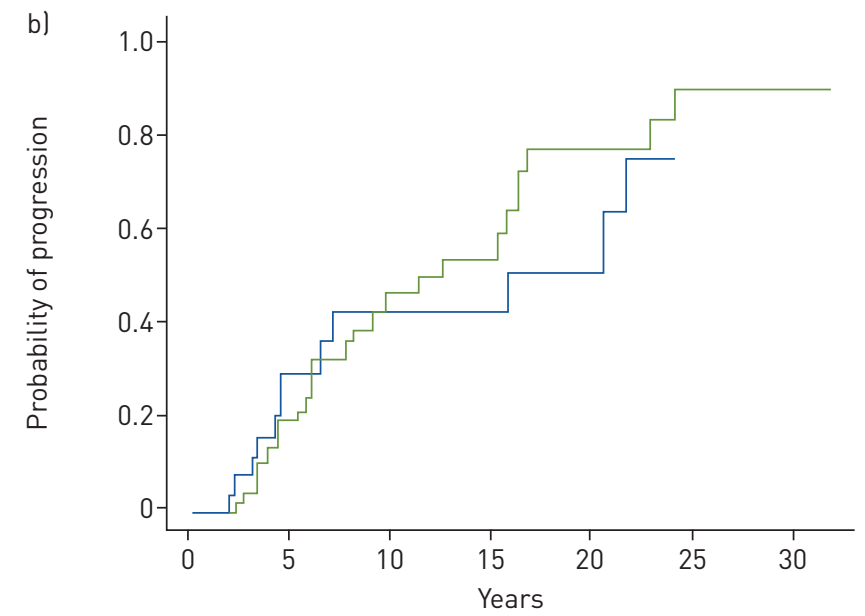

Patients at risk

$\begin{array}{lrcccccc}\text { BRAFV } 600 \mathrm{E} & 31 & 15 & 7 & 5 & 3 & 0 & 0 \\ \text { No BRAFV600E } & 52 & 29 & 13 & 8 & 4 & 1 & 1\end{array}$

FIGURE 5 Cumulative incidence of disease progression among all Langerhans cell histiocytosis (LCH) patients whose lesions were genotyped for the presence of the $B R A F^{\mathrm{V} 600 \mathrm{E}}$ mutation. a) Disease progression among the 117 patients tested according to the presence or absence of the $B R A F^{V 600 E}$ mutation, based on the assessment of the global outcome of their LCH localisations. b) The same comparison for the 83 pulmonary Langerhans cell histiocytosis (PLCH) patients at diagnosis who experienced pulmonary progression during the study period. 
TABLE 4 Multivariable analysis of factors associated with pulmonary outcome among the 83 pulmonary Langerhans cell histiocytosis (PLCH) patients at diagnosis ${ }^{\#}$

\begin{tabular}{lcc} 
Characteristic & Hazard ratio $(95 \%$ CI) & p-value \\
\hline Age at diagnosis & $1.03(1.00-1.05)$ & 0.083 \\
Airflow obstruction & $2.00(1.05-3.84)$ & 0.036
\end{tabular}

\#: airflow obstruction (forced expiratory volume in $1 \mathrm{~s}\left(\mathrm{FEV}_{1}\right) /$ forced vital capacity (FVC) ratio $\left.<70 \%\right)$.

paediatric $\mathrm{LCH}$, but close to the $42 \%$ reported by Heritien et al. [28] in paediatric LCH with lung involvement. Conversely, we identified $B R A F^{\mathrm{N} 486}{ }^{\mathrm{P} 490}$ deletions in up to $30 \%$ of our cases, in similar proportions from both WES and a dedicated pyrosequencing assay, which is much higher than the $6 \%$ frequency reported in paediatric LCH [19]. In contrast, the MAP2K1 alterations observed in this series occurred in a similar proportion as that reported in paediatric LCH (14.5\% and $12 \%$, respectively) [19]. Finally, no isolated KRAS mutations were identified in PLCH and, thus, our results do not support a role for this mutation in the development of PLCH lesions, unlike that recently suggested in a murine model in which a KRAS mutation was induced in lung myeloid cells [14].

The identification of these different MAPK alterations has an impact on MAPK-targeted treatment. While the $B R A F^{\mathrm{V} 600 \mathrm{E}}$ mutation is sensitive to BRAF inhibitors [32,33], BRAF $F^{\mathrm{N} 486 \_\mathrm{P} 490}$ deletion was shown to be relatively resistant to "first-generation" $B R A F^{\mathrm{V} 600 \mathrm{E}}$ inhibitors but sensitive to MEK inhibitors [19]. Similarly, LCH patients whose lesions harbour MAP2K1 mutations were shown to respond to MEK inhibitors [19, 34-36].

In this series of exclusively LCH cases, only one lesion contained molecular alterations involved in myeloid haematological disorders. This case included a TET2 mutation as well as in-frame duplication in FLT3, concurrently with $B R A F^{\mathrm{V} 600 \mathrm{E}}$ and $N R A S^{\mathrm{G} 12 \mathrm{D}}$ mutations. TET2 is widely involved in haematological malignancies and in clonal haematopoiesis of indeterminate potential [37, 38]. The in-frame duplication in FLT3 found here corresponds to a recurrent alteration observed in acute myeloid leukaemia [39]. At more than 4 years of follow-up, our patient did not develop any haematological disorders. The rare observation of molecular alterations in myeloid neoplasms is contrary to what has been reported in ECD and may be explained by the younger age of our patients compared with ECD patients [22].

An important result of this study in the clinical context is the absence of an association between the $B R A F^{\mathrm{V} 600 \mathrm{E}}$ mutation (tested in all cases) and either the initial presentation or the outcome of the patients. This result contrasts with that found in paediatric $\mathrm{LCH}$, in which the $B R A F^{\mathrm{V} 600 \mathrm{E}}$ mutation was associated with recurrence, severity and resistance to first-line therapy $[15,28]$. However, an important difference in adult LCH is that risk organ involvement (i.e. liver, spleen, or haematological system), which is associated with disease severity in paediatric LCH [1], is rarely present [20] (as was the case in the present series).

In this large cohort of PLCH patients, we did not find any association between smoking and $B R A F^{\mathrm{V} 600 \mathrm{E}}$ status, contrary to that previously suggested based on a small series of patients [5]. Importantly, the outcome of PLCH patients based on lung function variations over time was not influenced by the $B R A F^{\mathrm{V} 600 \mathrm{E}}$ status of their lesions. The nearly $50 \%$ of patients whose pulmonary involvement worsened during the study, in which patients were followed for a 6-year median time, was a similar proportion to that we previously observed at 5 years in a smaller retrospective multicentre study [40]. In contrast, airflow obstruction at diagnosis was a predictive factor of worsening of lung function during follow-up in this large cohort study, in which the data were prospectively registered.

Although our study population was representative of all histologically confirmed adult LCH cases seen at our centre, it may not reflect patients with isolated mild PLCH for whom a surgical lung biopsy is not always performed. However, these patients with a presumptive diagnosis retained on a clinical and imaging basis usually do not progress [2]. Thus, the findings of the present study are clinically meaningful. Similarly, because the LCH recruitment of our centre is orientated towards PLCH, the lack of clinical impact of the $B R A F^{\mathrm{V} 600 \mathrm{E}}$ mutation found in this study needs to be confirmed in a series of adult $\mathrm{LCH}$ cases without lung involvement.

In summary, MAPK alterations are present in most lesions from adult LCH patients, particularly in $\mathrm{PLCH}$. The search for alterations involved in MAPK pathway activation, including BRAF ${ }^{\mathrm{N} 486{ }^{2} \mathrm{P} 490}$ deletion, is important to guide the choice of targeted treatment in selected patients with refractory progressive $\mathrm{LCH}$.

Acknowledgments: The authors thank C. Bole-Feysot, M. Zarhrate and M. Parisot from the Imagine Institute (Paris, France) for WES genotyping. The authors are grateful to Omar Abdel-Wahab (Memorial Sloan Kettering Cancer Center, 
New York, USA) for his critical reading of the manuscript. The authors thank M. Mao and E. Savariau (Assistance Publique-Hôpitaux de Paris; Service de Pneumologie, Hôpital Saint-Louis, Paris, France) for their technical assistance.

Support statement: This study was supported by a grant from the Legs Poix 2016 Chancellerie des Universités de Paris, France. Funding information for this article has been deposited with the Crossref Funder Registry.

Conflict of interest: F. Jouenne has nothing to disclose. S. Chevret has nothing to disclose. E. Bugnet has nothing to disclose. E. Clappier has nothing to disclose. G. Lorillon reports travel/accommodation from Vitalaire and Chiesi, outside the submitted work. V. Meignin has nothing to disclose. A. Sadoux has nothing to disclose. S. Cohen has nothing to disclose. A. Haziot has nothing to disclose. A. How-Kit has nothing to disclose. C. Kannengiesser has nothing to disclose. C. Lebbé reports personal fees for consultancy, lectures and advisory board work from Amgen, grants and personal fees for consultancy, lectures, advisory board work and travel to meetings from BMS, grants and personal fees for consultancy, advisory board work and travel to meetings from MSD, grants and personal fees for consultancy, lectures and advisory board work from Roche and Novartis, personal fees for consultancy from Pierre Fabre, Sanofi and Merck Serono, and personal fees from Pfizer and Incyte, outside the submitted work. D. Gossot reports personal fees from Delacroix-Chevalier (instrument manufacturer), outside the submitted work. S. Mourah reports consultancy for Novartis and Roche, outside the submitted work. A. Tazi reports personal fees for lectures from BMS and travel/accommodation fees from Boehringer Ingelheim, Teva, Vitalaire and AstraZeneca, outside the submitted work.

\section{References}

Allen CE, Merad M, McClain KL. Langerhans-cell histiocytosis. N Engl J Med 2018; 379: 856-868.

2 Vassallo R, Harari S, Tazi A. Current understanding and management of pulmonary Langerhans cell histiocytosis. Thorax 2017; 72: 937-945.

3 Badalian-Very G, Vergilio JA, Degar BA, et al. Recurrent BRAF mutations in Langerhans cell histiocytosis. Blood 2010; 116: 1919-1923.

4 Chilosi M, Facchetti F, Calio A, et al. Oncogene-induced senescence distinguishes indolent from aggressive forms of pulmonary and non-pulmonary Langerhans cell histiocytosis. Leuk Lymphoma 2014; 55: 2620-2626.

5 Roden AC, $\mathrm{Hu}$ X, Kip S, et al. BRAF V600E expression in Langerhans cell histiocytosis: clinical and immunohistochemical study on 25 pulmonary and 54 extrapulmonary cases. Am J Surg Pathol 2014; 38: 548-551.

6 Kamionek M, Ahmadi Moghaddam P, Sakhdari A, et al. Mutually exclusive extracellular signal-regulated kinase pathway mutations are present in different stages of multi-focal pulmonary Langerhans cell histiocytosis supporting clonal nature of the disease. Histopathology 2016; 69: 499-509.

7 Mourah S, How-Kit A, Meignin V, et al. Recurrent NRAS mutations in pulmonary Langerhans cell histiocytosis. Eur Respir J 2016; 47: 1785-1796.

8 Alayed K, Medeiros LJ, Patel KP, et al. BRAF and MAP2K1 mutations in Langerhans cell histiocytosis: a study of 50 cases. Hum Pathol 2016; 52: 61-67.

9 Zeng K, Ohshima K, Liu Y, et al. BRAFV600E and MAP2K1 mutations in Langerhans cell histiocytosis occur predominantly in children. Hematol Oncol 2017; 35: 845-851.

10 Selway JL, Harikumar PE, Chu A, et al. Genetic homogeneity of adult Langerhans cell histiocytosis lesions: insights from BRAF ${ }^{\mathrm{V} 600 \mathrm{E}}$ mutations in adult populations. Oncol Lett 2017; 14: 4449-4454.

11 Brown NA, Furtado LV, Betz BL, et al. High prevalence of somatic MAP2K1 mutations in BRAF V600E-negative Langerhans cell histiocytosis. Blood 2014; 124: 1655-1658.

12 Chakraborty R, Hampton OA, Shen X, et al. Mutually exclusive recurrent somatic mutations in MAP2K1 and $B R A F$ support a central role for ERK activation in LCH pathogenesis. Blood 2014; 124: 3007-3015.

13 Nelson DS, van Halteren A, Quispel WT, et al. MAP2K1 and MAP3K1 mutations in Langerhans cell histiocytosis. Genes Chromosomes Cancer 2015; 54: 361-368.

14 Kamata T, Giblett S, Pritchard C. KRAS ${ }^{\mathrm{G} 12 \mathrm{D}}$ expression in lung-resident myeloid cells promotes pulmonary LCH-like neoplasm sensitive to statin treatment. Blood 2017; 130: 514-526.

15 Berres ML, Lim KP, Peters T, et al. BRAF-V600E expression in precursor versus differentiated dendritic cells defines clinically distinct LCH risk groups. J Exp Med 2014; 211: 669-683.

16 Thevenon J, Michot C, Bole C, et al. RPL10 mutation segregating in a family with X-linked syndromic intellectual disability. Am J Med Genet A 2015; 167A: 1908-1912.

17 Cancer Genome Atlas Network. Genomic classification of cutaneous melanoma. Cell 2015; 161: 1681-1696.

18 Papaemmanuil E, Gerstung M, Bullinger L, et al. Genomic classification and prognosis in acute myeloid leukemia. N Engl J Med 2016; 374: 2209-2221.

19 Chakraborty R, Burke TM, Hampton OA, et al. Alternative genetic mechanisms of BRAF activation in Langerhans cell histiocytosis. Blood 2016; 128: 2533-2537.

20 Tazi A, Lorillon G, Haroche J, et al. Vinblastine chemotherapy in adult patients with Langerhans cell histiocytosis: a multicenter retrospective study. Orphanet J Rare Dis 2017; 12: 95.

21 Tazi A, de Margerie C, Naccache JM, et al. The natural history of adult pulmonary Langerhans cell histiocytosis: a prospective multicentre study. Orphanet J Rare Dis 2015; 10: 30.

22 Papo M, Diamond EL, Cohen-Aubart F, et al. High prevalence of myeloid neoplasms in adults with non-Langerhans cell histiocytosis. Blood 2017; 130: 1007-1013.

23 Paik PK, Arcila ME, Fara M, et al. Clinical characteristics of patients with lung adenocarcinomas harboring BRAF mutations. J Clin Oncol 2011; 29: 2046-2051.

24 Yao Z, Yaeger R, Rodrik-Outmezguine VS, et al. Tumours with class 3 BRAF mutants are sensitive to the inhibition of activated RAS. Nature 2017; 548: 234-238.

25 Choi YL, Soda M, Ueno T, et al. Oncogenic MAP2K1 mutations in human epithelial tumors. Carcinogenesis 2012; 33: 956-961.

26 Marks JL, Gong Y, Chitale D, et al. Novel MEK1 mutation identified by mutational analysis of epidermal growth factor receptor signaling pathway genes in lung adenocarcinoma. Cancer Res 2008; 68: 5524-5528. 
27 Cao JN, Shafee N, Vickery L, et al. Mitogen-activated protein/extracellular signal-regulated kinase kinase $1^{\text {act} /}$ tubulin interaction is an important determinant of mitotic stability in cultured HT1080 human fibrosarcoma cells. Cancer Res 2010; 70: 6004-6014.

28 Héritier S, Emile JF, Barkaoui MA, et al. BRAF mutation correlates with high-risk Langerhans cell histiocytosis and increased resistance to first-line therapy. J Clin Oncol 2016; 34: 3023-3030.

29 Barbour AP, Tang YH, Armour N, et al. BRAF mutation status is an independent prognostic factor for resected stage IIIB and IIIC melanoma: implications for melanoma staging and adjuvant therapy. Eur J Cancer 2014; 50: 2668-2676.

30 Leeksma AC, Taylor J, Wu B, et al. Clonal diversity predicts adverse outcome in chronic lymphocytic leukemia. Leukemia 2019; 33: 390-402.

31 Zarnegar S, Durham BH, Khattar P, et al. Novel activating BRAF fusion identifies a recurrent alternative mechanism for ERK activation in pediatric Langerhans cell histiocytosis. Pediatr Blood Cancer 2018; 65: e26699.

32 Diamond EL, Subbiah V, Lockhart AC, et al. Vemurafenib for BRAF V600-mutant Erdheim-Chester disease and Langerhans cell histiocytosis: analysis of data from the histology-independent, phase 2, open-label VE-BASKET study. JAMA Oncol 2018; 4: 384-388.

33 Haroche J, Cohen-Aubart F, Emile JF, et al. Reproducible and sustained efficacy of targeted therapy with vemurafenib in patients with $B R A F^{\mathrm{V} 600 \mathrm{E}}$-mutated Erdheim-Chester disease. J Clin Oncol 2015; 33: 411-418.

34 Lee LH, Gasilina A, Roychoudhury J, et al. Real-time genomic profiling of histiocytoses identifies early-kinase domain BRAF alterations while improving treatment outcomes. JCI Insight 2017; 2: e89473.

35 Lorillon G, Jouenne F, Baroudjian B, et al. Response to trametinib of a pulmonary Langerhans cell histiocytosis harboring a MAP2K1 deletion. Am J Respir Crit Care Med 2018; 198: 675-678.

36 Diamond EL, Durham BH, Ulaner GA, et al. Efficacy of MEK inhibition in patients with histiocytic neoplasms. Nature 2019; 567: 521-524.

37 Cancer Genome Atlas Research Network, Ley TJ, Miller C, et al. Genomic and epigenomic landscapes of adult de novo acute myeloid leukemia. N Engl J Med 2013; 368: 2059-2074.

38 Genovese G, Kähler AK, Handsaker RE, et al. Clonal hematopoiesis and blood-cancer risk inferred from blood DNA sequence. N Engl J Med 2014; 371: 2477-2487.

39 Döhner H, Estey E, Grimwade D, et al. Diagnosis and management of AML in adults: 2017 ELN recommendations from an international expert panel. Blood 2017; 129: 424-447.

40 Tazi A, Marc K, Dominique S, et al. Serial computed tomography and lung function testing in pulmonary Langerhans' cell histiocytosis. Eur Respir J 2012; 40: 905-912. 